\title{
Cardiopulmonary Bypass Strategy to Facilitate Transfusion-Free Congenital Heart Surgery in Neonates and Infants
}

\author{
Wolfgang Boettcher ${ }^{1}$ Frank Dehmel ${ }^{1}$ Mathias Redlin ${ }^{2}$ Nicodème Sinzobahamvya ${ }^{3}$ Joachim Photiadis $^{3}$ \\ ${ }^{1}$ Division of Cardiovascular Perfusion, Department of Cardiothoracic \\ and Vascular Surgery, Deutsches Herzzentrum Berlin, Berlin, \\ Germany \\ ${ }^{2}$ Department of Anesthesiology, Deutsches Herzzentrum Berlin, \\ Berlin, Germany \\ ${ }^{3}$ Department of Congenital Heart Surgery - Pediatric Heart Surgery, \\ Address for correspondence Nicodème Sinzobahamvya, MD, \\ Department of Congenital Heart Surgery - Pediatric Heart Surgery, \\ Deutsches Herzzentrum Berlin, Stiftung des bürgerlichen Rechts, \\ Augustenburger Platz 1, 13353 Berlin, Germany \\ (e-mail: n.sinzobahamvya@gmail.com).
} Deutsches Herzzentrum Berlin, Berlin, Germany

Thorac Cardiovasc Surg 2020;68:2-14.
Abstract
Keyword
- cardiopulmonary bypass
- CPB
- blood transfusion
- neonate
- infant
- congenital heart disease
- CHD

Priming the cardiopulmonary bypass (CPB) circuit without the addition of homologous blood constitutes the basis of blood-saving strategies in open-heart surgery. For lowweight patients, in particular neonates and infants, this implies avoidance of excessive hemodilution during extracorporeal circulation. The circuit has to be miniaturized and tubing must be cut as short as possible to reduce the priming volume to prevent unacceptable hemodilution with initiating CPB. During perfusion, measures should be taken to prevent blood loss from the primary circuit to avoid replacement by additional volume. Favorable factors such as mild hypothermia/normothermia and high heparin concentrations during extracorporeal circulation promote earlier hemostasis after coming off bypass.

Lower mortality score, first chest entry, higher hemoglobin concentration before going on bypass, and shorter CPB duration support transfusion-free CPB procedure. Reduced postoperative morbidity and mortality were observed when CPB was performed without blood transfusion. In our experience, this can be achieved in at least $70 \%$ of CPBs, even in low-weight patients.

Bloodless CPB circuit priming should become a widespread reality, even in neonates and young infants, in any open-heart procedure.

\section{Introduction}

Cardiopulmonary bypass ( $\mathrm{CPB}$ ) induces several deleterious effects and is responsible per se for a certain postoperative morbidity, especially in pediatric cardiovascular surgery. This is partially due to the traditional use of donor blood, particularly in neonates and infants. Indeed, complications related to blood transfusion are well documented, such as infection transmission, allergic reactions, and isoimmuniza- tion. Today, congenital heart surgery is still one of those disciplines with the highest demand of donor blood.

Over the years, a number of cardiac surgical units promoted blood-saving strategies in adults. However, blood sparing programs for pediatric patients are still exceptional. At the German Heart Center (Deutsches Herzzentrum) Berlin, pediatric $\mathrm{CPB}$ circuits were adapted to such extent that all open-heart operations have been performed with bloodless received

May 24, 2019

accepted after revision

September 9, 2019

published online

November 3, 2019 (c) 2020 Georg Thieme Verlag KG Stuttgart · New York
DOI https://doi.org/ 10.1055/s-0039-1700529. ISSN 0171-6425. 
priming volume for more than 5 years regardless of patient's weight, even in neonates and infants.

After a short historical review, this article will present possible $\mathrm{CPB}$ modifications and techniques to facilitate transfusion-free congenital heart surgery and describe how perfusion may be performed. It will present results of this strategy and conclude on the perspectives of blood conservation approach in congenital heart surgery. Asanguineous circuit priming should become standard in pediatric congenital heart surgery as well.

\section{A Brief Historical Review}

With the introduction of the heart-lung machine in the 1950s, the circuit had to be filled with whole blood or blood components. In the morning of the operation day, several donors were invited to donate their blood. ${ }^{1}$ Despite first reports by Neptune et al and by Panico and Neptune ${ }^{2,3}$ on bloodless priming 60 years ago, in those days, the amount of priming necessary was too large compared with patient's own blood volume, even for adult patients. In 1965, Proctor and De Bono designed the first low priming volume oxygenator for adult patients to reduce the "possible morbidity arising from the use of large quantities of homologous blood." 4 Since the early 1970s, a widespread implementation of hemodilution with asanguineous circuit filling is common in adults. It was actually found that hemodilution improves tissues perfusion and oxygen delivery by decreasing blood viscosity and releasing peripheral vascular resistance. Priming volume was progressively reduced over time from more than $2000 \mathrm{~mL}$ down to often less than $1 \mathrm{~L}$ for adult patients. Thus, the recommendation of the Society of Thoracic Surgeons to use bloodless CPB circuit ${ }^{5}$ can nowadays be considered and achieved.

Contrasting to the situation in adult patients, the evolution to bloodless priming of pediatric $\mathrm{CPB}$ circuit was much slower because of the mismatch of priming volumes far in excess of the small blood circulating volume. ${ }^{6-8}$ In the mid-sixties, Baffes et $\mathrm{al}^{9}$ mentioned that "it is equally certain that present methods of perfusion in small infants are hazardous and should be applied only in extraordinary circumstances." In those days, most of the successful operations in pediatrics were performed in deep hypothermic circulatory arrest to limit the period of CPB to the time needed for further cooling after surface hypothermia and rewarming. ${ }^{10,11}$ Only one report dealt with bloodless CPB in pediatrics with inevitable excessive hemodilution. ${ }^{12}$

First, in 1971, Turina et al ${ }^{13-15}$ presented a sophisticated extracorporeal unit for neonates with a priming volume of less than 320 to $350 \mathrm{~mL}$ and in 1972 noted that "reduction in prime volume is a consideration of utmost importance in infant perfusion." He incorporated a $1 \mathrm{~m}^{2}$ Landé-Edwards membrane oxygenator and a venous roller pump, which generated the desired amount of suction on the venous line.

In the early eighties, several workers reported first case reports on open-heart surgery without donor blood only in children of Jehovah's Witnesses. ${ }^{16-19}$ In the late eighties, the advent of vacuum-assisted drainage (VAVD) significantly contributed to further reduction of the circulating extracorporeal volume. ${ }^{20-22}$ With VAVD, Wabeke et al in 1987 showed that it was possible to develop an extracorporeal circuit with a static priming volume of only $90 \mathrm{~mL}$, which allowed priming without the use of donor blood even in a rabbit model. ${ }^{23}$ Then, the first commercially available pediatric membrane oxygenators were offered. ${ }^{24,25}$ In 1991, Conley reported open-heart operation in a child weighing $15 \mathrm{~kg}$ without homologous blood transfusion. ${ }^{26}$ His CPB circuit consisted of one of these new pediatric membrane oxygenators. More and more case reports were published thereafter. Our own first publication on circuit miniaturization was in 2003 in a newborn who successfully underwent transfusion-free $\mathrm{CPB}$ for an arterial switch operation. $^{27}$

\section{CPB Adaptation for Bloodless Open-Heart Operation in Low-Weight Patients}

There are prerequisites to contemplate transfusion-free open-heart operation. Suitable and proper tools such as oxygenator, filter, and reservoir have to be chosen and correctly positioned. Volume priming must be restricted to the patient's weight to achieve the desired hematocrit (Hct) level during CPB course.

\section{Prerequisites}

The patient should be normo- or hypervolemic with red blood cell (RBC) volume at least in the normal range to prevent excessive hemodilution.

Unlike cardiac surgery in adults, pediatric cardiac surgery has not yet established consensual blood management for extracorporeal circulation. Therefore, anemic patients should be transfused with blood before operation or, if time allows, should receive therapy to promote erythropoiesis. It seems to be easier to manage corrective surgery in cyanotic patients with their initially high Hct, such as an arterial switch operation of a transposition of the great arteries. Another essential prerequisite is at least functional coagulation state prior to surgery. The quantity of functional platelets prior to extracorporeal circulation has to be within normal limits. In addition, all other constituents of the coagulation system should show normal values, as hemodilution due to the priming volume not only affects oxygen transport but also the platelet and humoral factor-dependent coagulation.

Team cooperation is essential. Preoperatively, it is important to prevent dehydration and maintain normal fluid balance. Euvolemia guarantees the best hemodynamic stability. Induction and maintenance of anesthesia should be done in a manner which is not followed by an active loss of peripheral resistance. Before operation, unnecessary blood sampling due to routine medical standards should be avoided. ${ }^{28}$ Medication leading to vasoplegia triggers the need for fluid application to counteract the resulting hypotension, tachycardia, and low cardiac output. Continuous application of vasodilating drugs leads to more amount of fluid administration. Every additional amount of bloodless volume given before the initiation of bypass steers further Hct reduction and hemodilution. The surgeon should apply meticulous surgical technique aimed at minimizing blood loss. 
The surgical team (surgeon, anesthetist, perfusionist) must agree to the lowest Hct and hemoglobin ( $\mathrm{Hb}$ ) levels that will be tolerated during $\mathrm{CPB}$ course. There is currently no consensus in the literature, as recently discussed. ${ }^{29}$ Several years ago, we defined transfusion trigger of $\mathrm{Hb}$ concentration less than $7 \mathrm{~g} / \mathrm{dL}$ during $\mathrm{CPB} .{ }^{30,31}$ While monitoring cerebral oxygenation by near-infrared spectroscopy to detect and avoid cerebral and caudal hypoxia, ${ }^{32}$ we recently adopted an $\mathrm{Hb}$ concentration of $8 \mathrm{~g} / \mathrm{dL}$, which corresponds to Hct level of approximately $24 \%{ }^{33}$ In the past, when the Hb threshold was fixed at $7 \mathrm{~g} / \mathrm{dL}$, we had to counteract with a higher perfusion flow of approximately $3 \mathrm{~L} / \mathrm{m}^{2} /$ minute, which is often impracticable, especially in smallest pediatric patients, occasionally due to longer periods of compromised venous return during systemic rewarming or perfusion in normothermia. But in cases of palliative surgery with ongoing cyanosis, the minimal target $\mathrm{Hb}$ concentration for weaning from CPB was fixed at $13 \mathrm{~g} / \mathrm{dL}^{33}$

\section{Material}

Cardiopulmonary Bypass Console/Mast-Mounted Pumps Two different types of pumps are in use today. The simplest and cheapest remains the roller pump, which only needs a tubing to be filled and de-aired. More sophisticated, and more expensive, is the centrifugal pump. In former years, the centrifugal pumps were easier to set in position since Vortex pumps were the first ones with the drive unit mounted remotely from the control unit. But today, there is a newer generation of consoles with their mast-mounted roller pumps that are also adjustable in height and position. ${ }^{34-36}$ Disadvantages of centrifugal pumps may be the higher prime volume as compared with a boot in the raceway of a small roller pump ${ }^{37}$ and, more importantly, the inaccuracy at low flow rates. Smaller roller pumps for lower pump rates only need shorter pump boots. ${ }^{38}$ Centrifugal pumps developed more recently also have a low priming volume. ${ }^{37,39}$

\section{Oxygenator/Arterial Line Filter/Tubing/Reservoir}

The oxygenator should take in the lowest static prime volume and meet the metabolic demands of the particular patient at the same time. The model of oxygenator used depends on the patient's body weight and height and also, at times, on the type of surgery planned or on the estimated time on bypass. Since the late eighties, smaller membrane oxygenators with less priming volume are available for neonates and infants. Those for older children are smaller than those for low weight adults. Recently, hollow fiber capillary oxygenators with integrated arterial line filter have been introduced in the market, which further contributes to the reduction of priming volume.

The inner diameter (ID) of the tubings should be as small as possible and limited by the pressure gradient or the resistance for the blood flow which is needed. For the arterial line, it is defined by the arterial line pressure, which is also influenced by the length of the tubing and the choice of the smallest possible arterial cannula. Concurrently, in neonates, an ID of $1 / 8$ inch is practical. Smaller diameter arterial tubing decreases priming volume, but it causes higher circuit pressure as well. For the venous line, the ID is limited by the amount of venous return, when it is only gravity-driven. This circumstance is counteracted with a higher amount of negative pressure with VAVD.

The integration of the venous reservoir within the cardiotomy reservoir also reduces the priming volume. It is, moreover, affected by the stipulated blood level in the venous reservoir, the design of which sometimes allows lower initial priming volume.

\section{Vacuum-Assisted Venous Drainage}

Wabeke et al stated in 1987: "Replacing gravity flow by negative pressure in the venous reservoir is the basic idea behind the design of this compact low volume heart-lung machine." ${ }^{23}$ According to Durandy, venous return is increased owing to VAVD. ${ }^{40,41}$ Increasing negative pressures on the venous line were not related to increased hemolysis. ${ }^{37,42,43}$ Maximal flow through a 3/16-inch tubing climbs further by $40 \%$. It is less influenced by gravity. Thus, by adequate positioning, the venous line can be shortened and the ID reduced. With these measures, the static priming volume is further reduced. ${ }^{27,41}$

\section{Positioning and Tubing Cutting}

To shorten the length of the tubing, the CPB console should be positioned as close as possible to the sterile field, thereby nearest to the very small cannulated infant. Turina et al recommended the following early in 1972: "Since the priming of the oxygenator, heat exchanger, and filter cannot be reduced significantly without impairing their effectiveness, further reduction in the priming volume of the system was achieved by setting the perfusion unit on the operating table."15

The arterial pump should be situated close to the outlet of the venous reservoir and the oxygenator inlet. The pumps of the cardiotomy suction should be positioned at the height of the inlet of the cardiotomy reservoir. The tubings connecting the pumps with the reservoir or oxygenator should measure only the necessary length to keep them as short as possible. When VAVD is in use, the inlet of the venous reservoir may be at the height of the patient's right heart. When an external arterial line filter is used, the bubble detector should be placed between the oxygenator outlet and the filter. The sterile field might therefore have its border directly downstream to the filter. These considerations are illustrated in - Figs. 1-5.

\section{Circuit Priming}

Static priming volume is defined as the fluid needed to fill and de-air circuit components and tubings to prevent the risk of air embolism. This priming volume determines $\mathrm{Hb}$ concentration and Hct level immediately after commencing CPB. Hct on CPB (HctCPB) can be estimated by the formula $\mathrm{HctCPB}=(\mathrm{PBV} \times \mathrm{Hct}) / \mathrm{TCV}$, in which PBV is the patient blood volume, Hct is the patient's Hct, and TCV is the total circulatory volume. TCV is the sum of PBV + circuit priming volume. ${ }^{44,45}$ Verification of a sufficient $\mathrm{Hb}$ concentration is of utmost importance before starting CPB, as shown in - Fig. $\mathbf{6}$. 


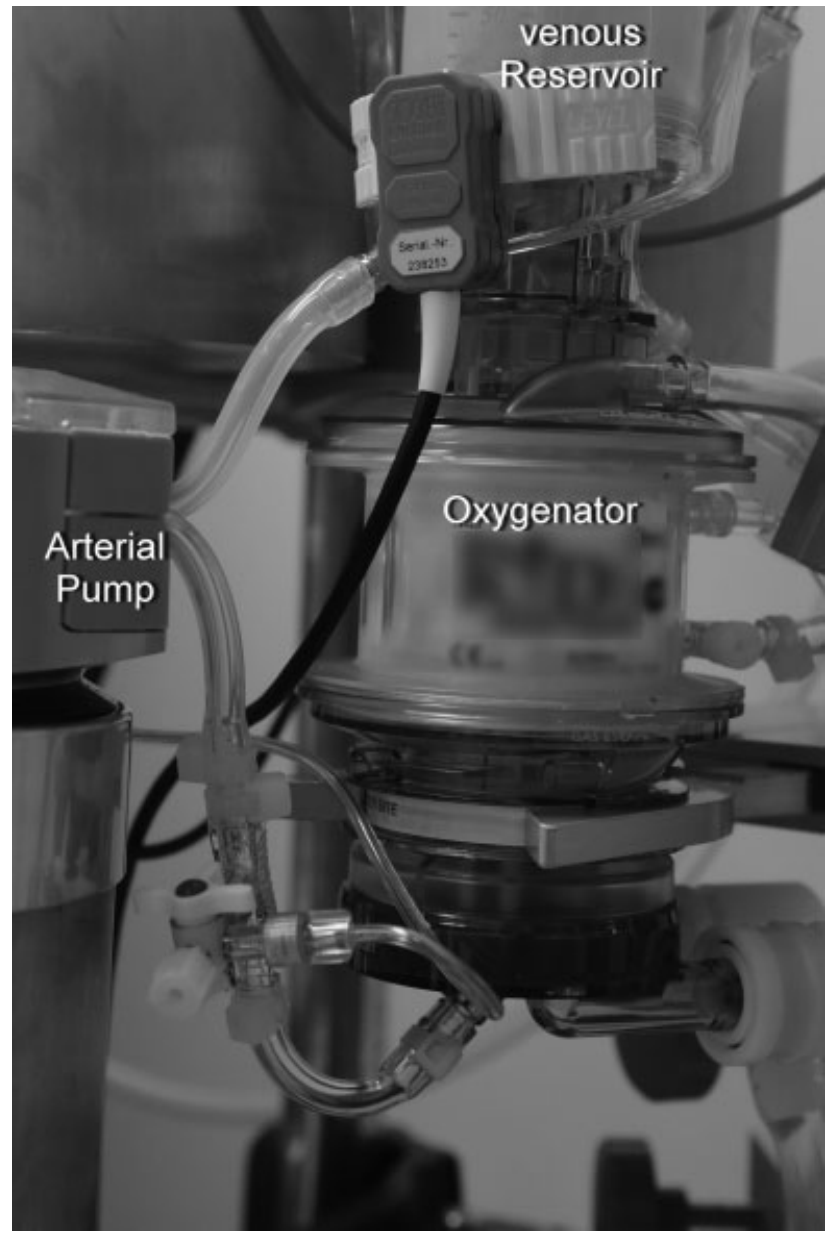

Fig. 1 Shortest tubings connecting the outlet of the venous reservoir to the arterial pump and to the inlet of the oxygenator.

In the instance where the priming volume is the same as the blood volume, Hct after CPB starts will be about half of the Hct before $\mathrm{CPB}$. When the static priming volume is lower, resulting Hct will be more than its half. It is desirable to construct an extracorporeal circuit with a static priming volume of up to one-third in relation to the patient's own blood volume so that Hct level observed after commencing CPB is at least three-fourths of the Hct level measured before CPB. By proceeding this way, addition of donor blood could be avoided in most of the cases, assuming that the preoperative Hct is at least in the normal range.

There is a great variety of expert opinions on the mixture of the priming volume. To avoid human errors in the compositions, it should be simple, small, nontoxic, nonallergic, and ideally like a physiological electrolyte solution. ${ }^{38}$ Practically, the bloodless bypass circuit has to be adapted to patient's weight so that predicted $\mathrm{Hb}$ concentration or Hct level is higher than the chosen threshold (minimal value) to indicate blood transfusion.

The kind and size of the oxygenator, tubing, and arterial pump boot that we currently use for neonates, infants, and young children are detailed in -Table 1. We could thus achieve the smallest ever attained priming volume of $73 \mathrm{~mL}$ for preterm patients weighing less than $2.5 \mathrm{~kg}^{28}$

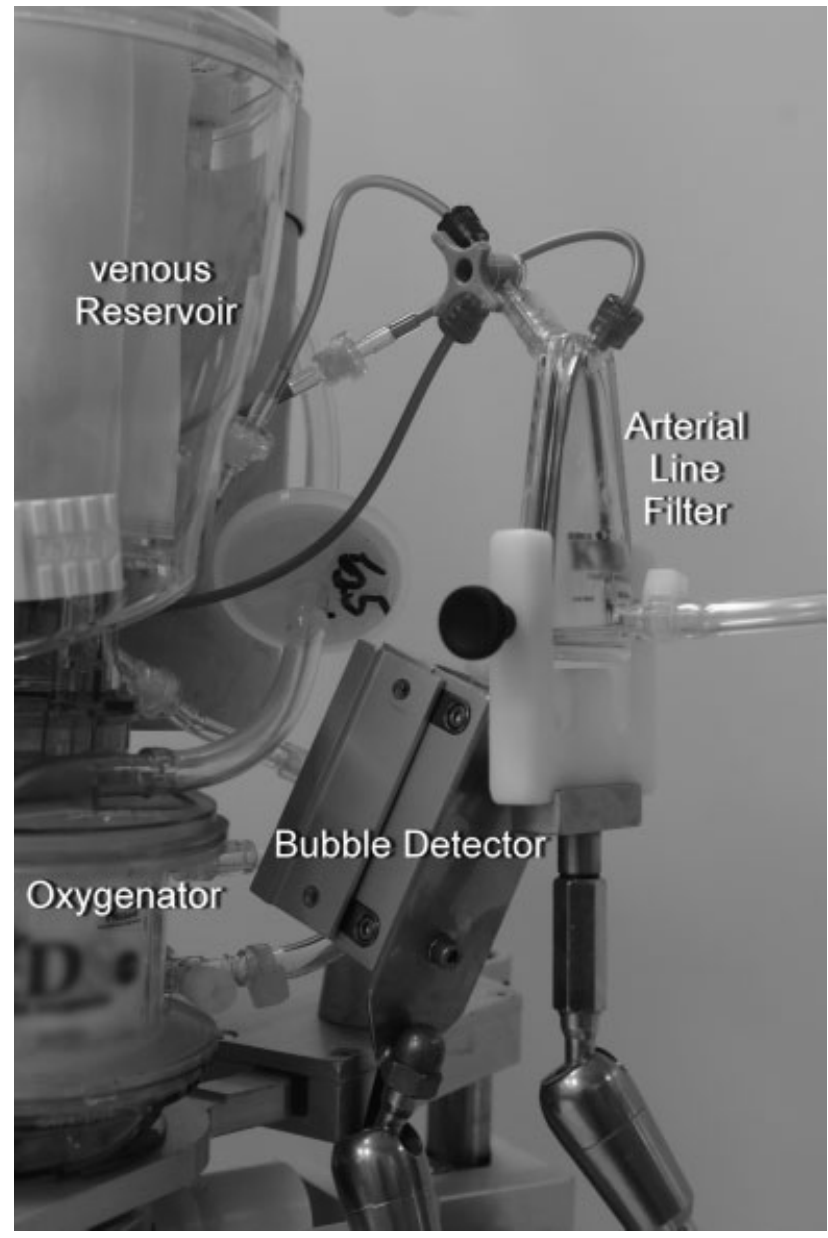

Fig. 2 Connection of the oxygenator outlet to the arterial line filter with the bubble detector.

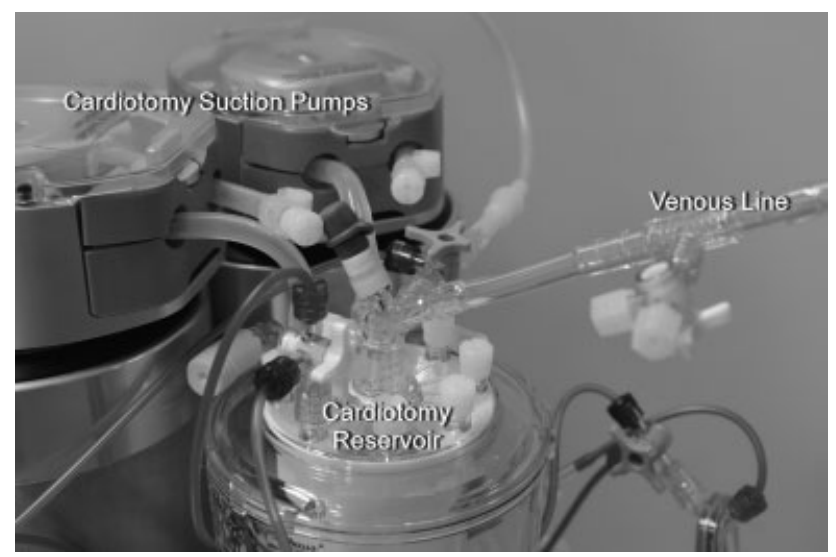

Fig. 3 Cardiotomy suction pumps with tubings (1/8 inch of internal diameter) in proximity with the inlet of the cardiotomy reservoir.

\section{Cardiopulmonary Bypass Run}

\section{Dynamic Priming Volume}

Aortic and venous cannulation and de-airing of the cannulas will decrease the patient's blood volume. The resulting hypovolemia is managed by a substitution of external volume or pharmacological vasoconstriction. Bloodless CPB must be commenced slowly, otherwise heart and whole 


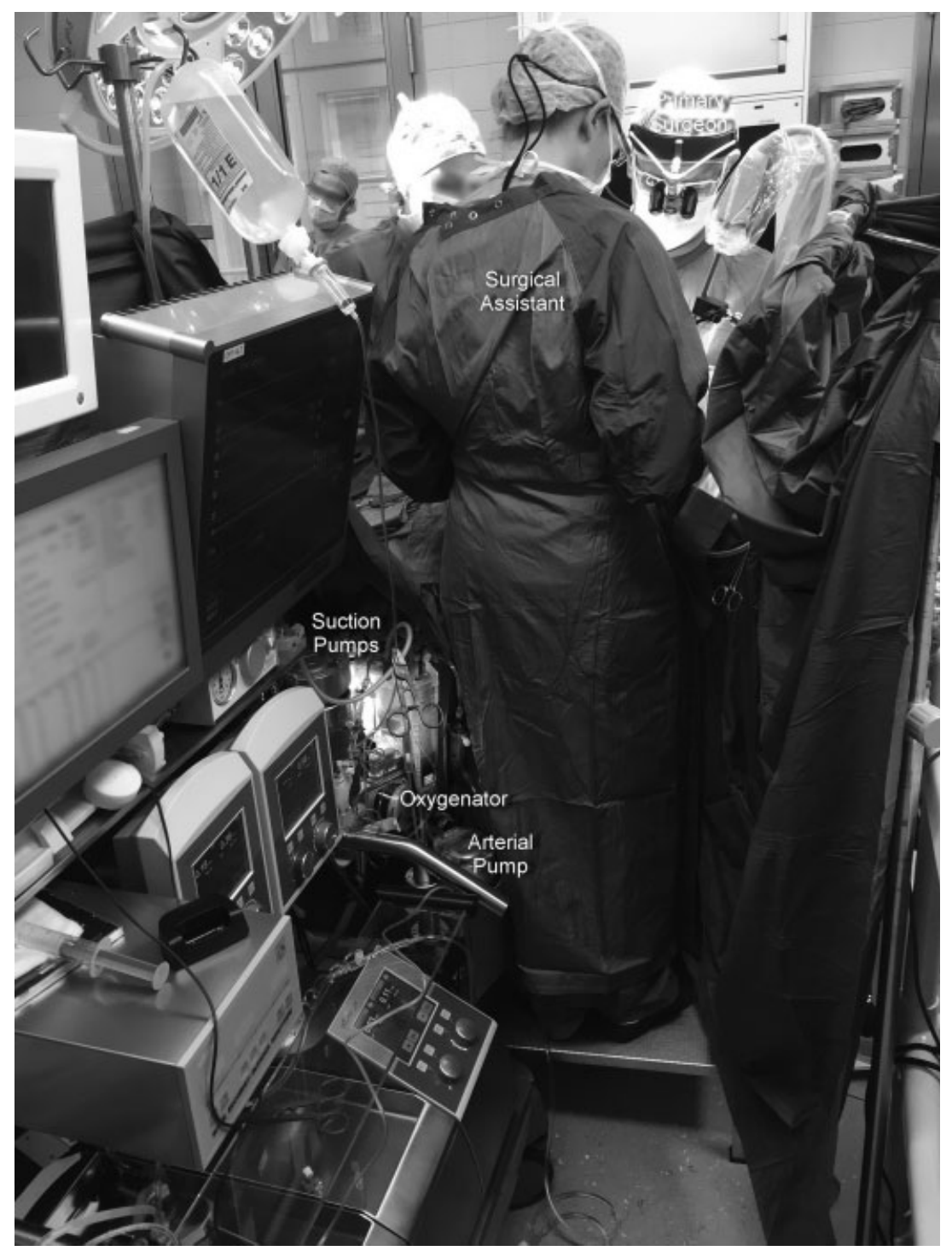

Fig. 4 A heart-lung machine positioned at the operation table.

body will be flushed by asanguineous fluid and thereby cardiac and end-organ function could be compromised. This is achieved by holding back some preload and keeping the left ventricle ejecting to maintain the coronary blood circulation until the asanguineous priming has mixed with the patient's own blood in the extracorporeal circuit.

After initial hemodilution by commencing CPB, further reduction of the Hct will take place when crystalloid cardioplegic solution is applied. The amount of dilution can be reduced by suctioning the cardioplegic solution from the coronary sinus or by spontaneous diuresis or ultrafiltration.

The amount of dynamic priming volume is predominantly affected by the cardiotomy suction. The suction lines notably increase the dynamic priming volume proportionally to the length of the tubings. The blood volume needed to fill these suction tubes during procedures such as venting the ventricle or de-airing the aortic root is missing at that time in the venous reservoir. It also takes some time to pass the cardiotomy reservoir before the returning blood finally enters the venous reservoir. The more pump suckers are used, the larger the dynamic priming volume will be. The even temporarily missing volume in the venous reservoir has to be replaced to maintain the extracorporeal circulation, otherwise the lowlevel detector alarms will intermittently stop the CPB and make a safe pump drive impossible, especially in neonatal patients.

Suction lines therefore have to be cut as short as possible to facilitate a transfusion-free CPB. Those longest tubing lines should have the smallest ID possible. Even a $1 / 8$-inch suction line would hold a blood volume of $8 \mathrm{~mL}$ (a suction line in adults often exceeds a length of $4 \mathrm{~m}$ ). Their number should be strictly limited to 2 . The use of a needle as a vent should be restricted, whenever possible, and safe.

\section{Decannulation}

Venous decannulation should be performed as soon as possible with weaning and coming off bypass. The content of the venous line is of importance for maintaining the preload of smaller patients without adding other asanguineous fluids. Arterial decannulation should be realized as 


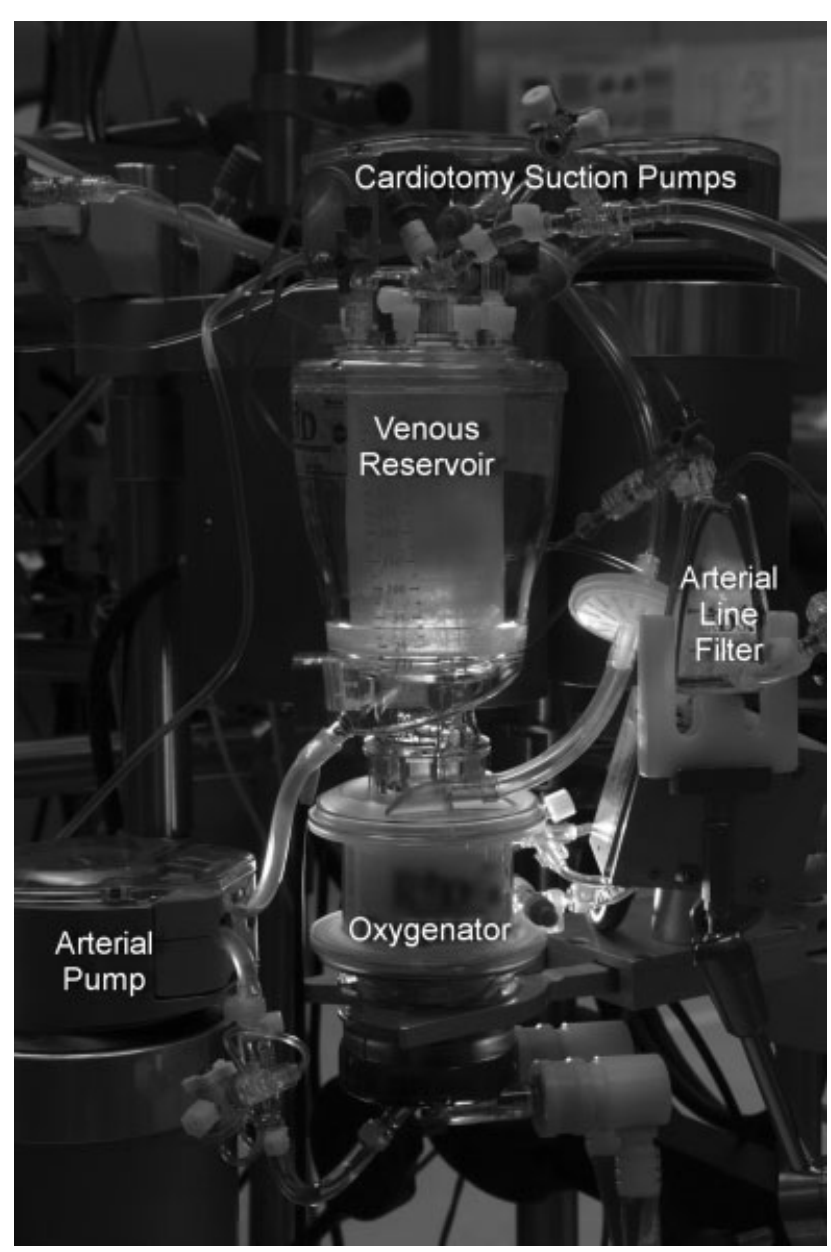

Fig. 5 Arterial pump on the left side, the oxygenator in the center, and arterial line filter on the right side of the picture. The suction pumps are on the upper side of the cardiotomy reservoir.

soon as hemodynamic stability of the patient is assured. The residual volume of the extracorporeal circuit, normally only 50 to $70 \mathrm{~mL}$ in patients up to $11 \mathrm{~kg}$ of birth weight, can be immediately retransfused by the anesthesiologist to achieve normovolemia and elevate the Hct level. It is helpful to administer the residual volume before or while protamine antagonization is started. We stopped modified ultrafiltration (MUF) more than a decade ago since this counteracts our blood sparing strategy by increasing priming volume. Additional blood volume would be necessary for de-airing the tubing to and from the filter and for the ultrafilter itself. After weaning from CPB usually only less than $60 \mathrm{~mL}$ blood is left in the circuit in patients with up to $10 \mathrm{~kg}$ of body weight. This residual volume will be given back to the patient immediately to generate a sufficient preload.

Commercially available ultrafilters are usually not coated like the other components of the circuit despite their large foreign surface area. Coating by albumin and platelets during the CBP run reduces the number of coagulation factors and might lead to coagulation problems after heparin reversal. Also, cytokine and inflammatory processes will be enhanced with increased foreign surface area.

MUF practice, which was important in the era of high pediatric priming volumes, became questionable. ${ }^{46}$ In brief, MUF after coming off bypass may be hemodynamically interesting, but it does not facilitate the blood-saving strategy.

\section{Anticoagulation/Coagulation Management}

Inadequate anticoagulation during CPB may lead to ineffective suppression of thrombin formation and may result in disorders of hemostasis and thrombosis in the postbypass period. It may, furthermore, impact inflammation. ${ }^{47}$ Koster et $\mathrm{al}^{31}$ had shown lower plasma concentrations of C5b-9, suggesting a beneficial effect on the inflammatory response with adequate concentrations of heparin. Activated clotting time (ACT) values are often affected by variables other than heparin, such as hypothermia and hemodilution. Several studies have shown a poor correlation between ACT values and plasma heparin concentrations. ${ }^{48-52}$ Protocols that allow more constant heparin concentration and precise estimation of the dose of protamine should be preferred, for example, Hepcon HMS (Medtronic, Minneapolis, Minnesota, United States). ${ }^{51}$ This, especially after prolonged $\mathrm{CPB}$, may lead to earlier hemostasis after coming off bypass, thereby reducing blood loss and transfusions. It might

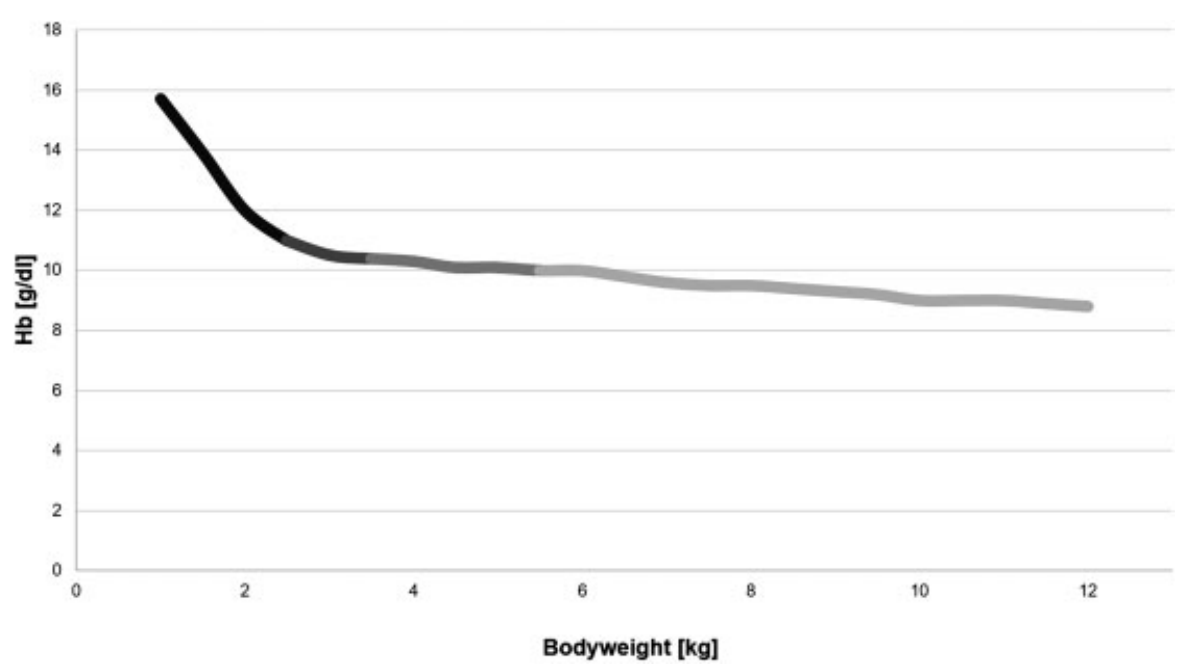

Fig. 6 Essential precardiopulmonary bypass concentration of hemoglobin to calculate a hemoglobin concentration of approximately $8 \mathrm{~g} / \mathrm{dL}$ on bypass after mixing the patient's blood with the priming volume of the extracorporeal circuit. 
Table 1 Weight-adjusted cardiopulmonary bypass circuits

\begin{tabular}{|l|l|l|l|l|l|l|}
\hline $\begin{array}{l}\text { Body weight } \\
(\mathrm{kg})\end{array}$ & Oxygenator & $\begin{array}{l}\text { Arterial line } \\
\text { filter }\end{array}$ & Arterial line & Venous line & $\begin{array}{l}\text { Arterial } \\
\text { pump boot }\end{array}$ & $\begin{array}{l}\text { Priming } \\
\text { volume }(\mathrm{mL})\end{array}$ \\
\hline$<2.5$ & Sorin Dideco D100 & $\begin{array}{l}\text { Sorin Dideco } \\
\text { D130 }\end{array}$ & $1 / 8$ inch of ID & $1 / 8$ inch of ID & $1 / 8$ inch of ID & 73 \\
\hline $2.5-3$ & Sorin Dideco D100 & $\begin{array}{l}\text { Sorin Dideco } \\
\text { D130 }\end{array}$ & $1 / 8$ inch of ID & $1 / 8$ inch of ID & $3 / 16$ inch of ID & 85 \\
\hline $3.1-5$ & Terumo Capiox FX05 & Integrated & $1 / 8$ inch of ID & $3 / 16$ inch of ID & $3 / 16$ inch of ID & 95 \\
\hline $5.1-10$ & Terumo Capiox FX05 & Integrated & $3 / 16$ inch of ID & $3 / 16$ inch of ID & $1 / 4$ inch of ID & 110 \\
\hline $11-25$ & Dideco D101 & $\begin{array}{l}\text { Sorin Dideco } \\
\text { D131 }\end{array}$ & $1 / 4$ inch of ID & $1 / 4$ inch of ID & $\begin{array}{l}1 / 4 \text { inch of ID } \\
\text { Adult roller pump }\end{array}$ & 300 \\
\hline
\end{tabular}

Abbreviation: ID, internal diameter.

also limit the risk of profound circulatory changes observed in some patients with protamine application.

In pediatrics, as an institutional standard, we commence $\mathrm{CPB}$ with higher heparin concentrations $\geq 6 \mathrm{IU} / \mathrm{mL}$ to achieve an ACT above 750 seconds. With this measure, we hope to suppress the activation of the coagulation system and the inflammatory response.

\section{Cardioplegia}

The use of blood cardioplegia constitutes additional extension of the extracorporeal circuit and therefore aggravates hemodilution. According to Datt et al, blood cardioplegia adds 31 to $52 \mathrm{~mL}$ of volume. ${ }^{37}$ This is comparable to the priming volume of an oxygenator. Crystalloid cardioplegic solution has the disadvantage of further temporary hemodilution when entering the primary circulation. Thus, it should either be eliminated at the coronary sinus whenever possible or removed by ultrafiltration, thereby limiting the time of temporary additional hemodilution. If removing crystalloid cardioplegic solution is impossible due to high collateral coronary blood flow, it is deemed preferable to remove this volume with conventional ultrafiltration. It is realistic to eliminate around $90 \%$ of the cardioplegic solution through suctioning from the coronary sinus, thereby preventing potential negative side effects of this solution such as contamination of the systemic blood flow.

\section{Ultrafiltration}

An ultrafiltration circuit is always an extension of the extracorporeal circuit, leading to further hemodilution. It can also be seen as an exposition of patients' blood to a large additional foreign surface. This surface is most often uncoated like the initial set up circuit and thus relatively large. Therefore, additional platelets and albumin will be lost with its use. When ultrafiltration is inevitable, the filter should be filled with the patient's blood only temporarily and emptied into the cardiotomy reservoir following every operation. An efficient hemoconcentrator with a low priming volume is preferable. The tubing connections to and from the filter should also be as short as possible to minimize dynamic priming volume. An additional pump is not essential when only the pressure gradient between the arterial line pressure and the venous line is used.

\section{Surgical Aspects}

Circuit miniaturization requires special attention to the necessary draping for sterility, resulting in a rather uncomfortable position and strain for the surgical assistant (-Fig. 4). With a standardized approach, it is safe, and, according to our experience, the whole team gets quickly used to it.

Dry-in and dry-out technique supports and reduces blood loss before and after CPB. Nonretrievable blood loss must be avoided.

Surgery should be ideally performed either in normothermia or mild hypothermia as the effects of more pronounced hypothermia on transcapillary fluid exchange, leading to greater postoperative fluid extravasation, are well documented. ${ }^{53}$ Moreover, the negative impact of lower temperatures on postoperative hemostasis is known. Increased blood loss and blood transfusion have been assigned to hypothermic perfusion, as well as modifications in endothelial-related coagulation, namely, protein $\mathrm{C}$, protein $\mathrm{S}$, and thrombomodulin.

Time on CPB should be reduced as much as possible, as this variable is a strong determinant factor to achieve transfusion-free CPB procedure. ${ }^{28,33}$

\section{Perioperative Blood Transfusion}

Stored packed RBCs (PRBCs) are depleted of 2,3-bisphosphoglycerate. PRBCs are known to promote the formation of proinflammatory cytokines and have a decreased deformability and increased adhesiveness and aggregability. ${ }^{54-56}$ Therefore, transfusion of PRBCs while on CPB should be avoided or at least postponed toward the end of CPB to limit the period of mechanical stress. Moreover, PRBCs in the priming volume or transfusion during bypass represent an arterial transfusion in contrast to the routine intravenous administration, with the pulmonary vasculature working as a potential protecting filter. There is a risk of impaired microcirculation or even embolization into the arterial microcapillary system induced by hemolysis and released free $\mathrm{Hb}$. This is known to be an efficient scavenger of nitric oxide. As a consequence, endothelial dysfunction can ensue. ${ }^{57,58}$

Division of one unit of PRBC in three parts-one for the potential use during bypass, one for the anesthesia, and one for the intensive care unit-may also be an effective measure to decrease the total amount of blood used and limit the exposure to a sole donor. 


\section{Results}

\section{Feasibility}

Feasibility of open-heart operations without homologous blood in neonates and infants is now established, albeit practiced by few centers. Most related studies are case reports, especially for newborns whose parents are Jehovah's Witnesses. But several papers have been published as series for infants with low body weight. ${ }^{59-65}$ The largest series in the literature concerning neonates $(n=173)$ was reported by our institution. ${ }^{66}$ The rate of complete transfusion-free operation was 29\% (51/173), and CPB could be performed without any addition of blood or blood products in $61 \%(105 / 173)$ of cases while maintaining $\mathrm{Hb}$ concentration above $8 \mathrm{~g} / \mathrm{dL}$ and monitoring cerebral and peripheral oxygenation by near-infrared spectroscopy. We recently reported on 452 patients with a body weight of up to $7 \mathrm{~kg}$ (mean: $4.7 \mathrm{~kg}$; range: $2.22-7 \mathrm{~kg}$ ) who received no transfusion during $\mathrm{CPB} .{ }^{67}$ Their last mean $\mathrm{Hb}$ value before CPB discontinuation was $9.8 \pm 1.8 \mathrm{~g} / \mathrm{dL}$.

Lower mortality score (according to the Society of Thoracic Surgeons and the European Association for Cardio-Thoracic Surgery ${ }^{68}$ ), first chest entry, higher $\mathrm{Hb}$ concentration before undergoing bypass, and shorter CPB duration support transfusion-free CPB procedure. ${ }^{28,69,70}$ In our experience, blood transfusion becomes inevitable during procedures belonging to STAT (The Society of Thoracic Surgeons-European Association for Cardio-Thoracic Surgery) category 5, such as the Norwood procedure. Palliative operation and ongoing cyanosis make transfusion inevitable. In this patient group, transfusion can usually be performed with the discontinuation of the extracorporeal circulation, which is the current practice in the last years in our unit. In corrective surgery, however, a growing percentage of transfusion-free CPB is possible even in newborn patients (-Fig. 7).

\section{Outcome}

Low priming volume $\mathrm{CPB}$ circuits, miniaturization, and the use of the smallest artificial surface of the oxygenator are likely to reduce blood/surface interaction and attenuate inflammatory reaction. Consequently, organ function should be better preserved. Perioperative blood transfusion enhances inflammatory response to $\mathrm{CPB}$ and increases myocardial and pulmonary dysfunction. ${ }^{44}$ Therefore, a better outcome is expected for transfusion-free open-heart procedures. Indeed, improved postoperative morbidity in terms of shorter duration of mechanical ventilation and stay at the intensive care unit has been reported. $^{29,32-34,60,65,67,69}$ The most recent publication from our institution also demonstrates reduced postoperative mortality when CPB is performed without blood transfusion. ${ }^{67}$ In our experience, we also noted improved coagulation parameters when asanguineous strategies were realized during CPB. This was confirmed by rotational thromboelastometry performed before coming off bypass (-Figs. 8-10).

It is to be noted that asanguineous priming not only helps to avoid blood transfusions in patients on CPB but also results in an overall reduction of transfusion requirements during hospital stay. ${ }^{29}$

\section{Perspectives and Conclusion}

Blood is a precious life-saving commodity, yet it is potentially dangerous and should be used with parsimonious precaution.

A functional alternative to replace the oxygen transport function of $\mathrm{Hb}$ without serious complications has not yet been found for human use. Therefore, blood transfusions remain indispensable to correct acute anemia that occurs during open-heart operations. Even though it is currently recommended that the Hct not be diluted below $24 \%$ in the new-born undergoing CPB for congenital heart disease, ${ }^{71}$ researchers should thrive to find out the lowest $\mathrm{Hb}$ concentration (highest hemodilution) compatible with acceptable metabolism and sound postoperative organ recovery to fix a realistic threshold for perioperative blood transfusion.

Inevitable blood transfusion during CPB course should be postponed as long as possible to the last moments of the extracorporeal circulation. Only PRBC units with the shortest

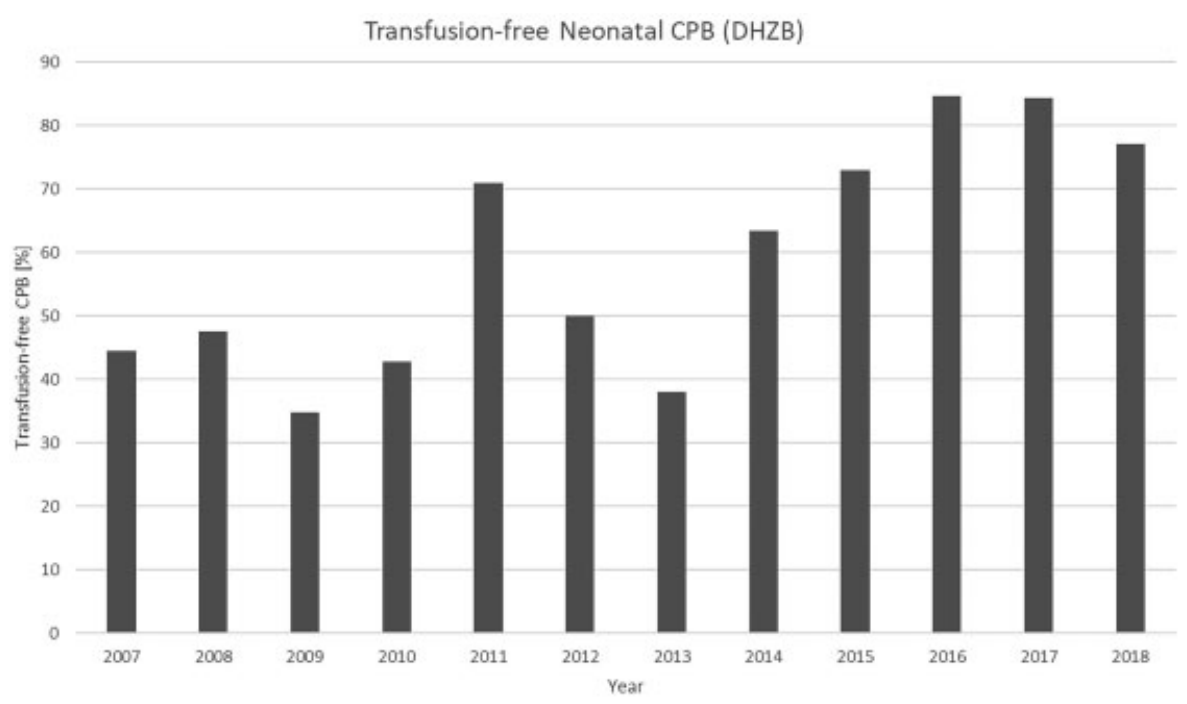

Fig. 7 Percentage of transfusion-free cardiopulmonary bypass in neonatal patients at the DHZB (2007-2018). 

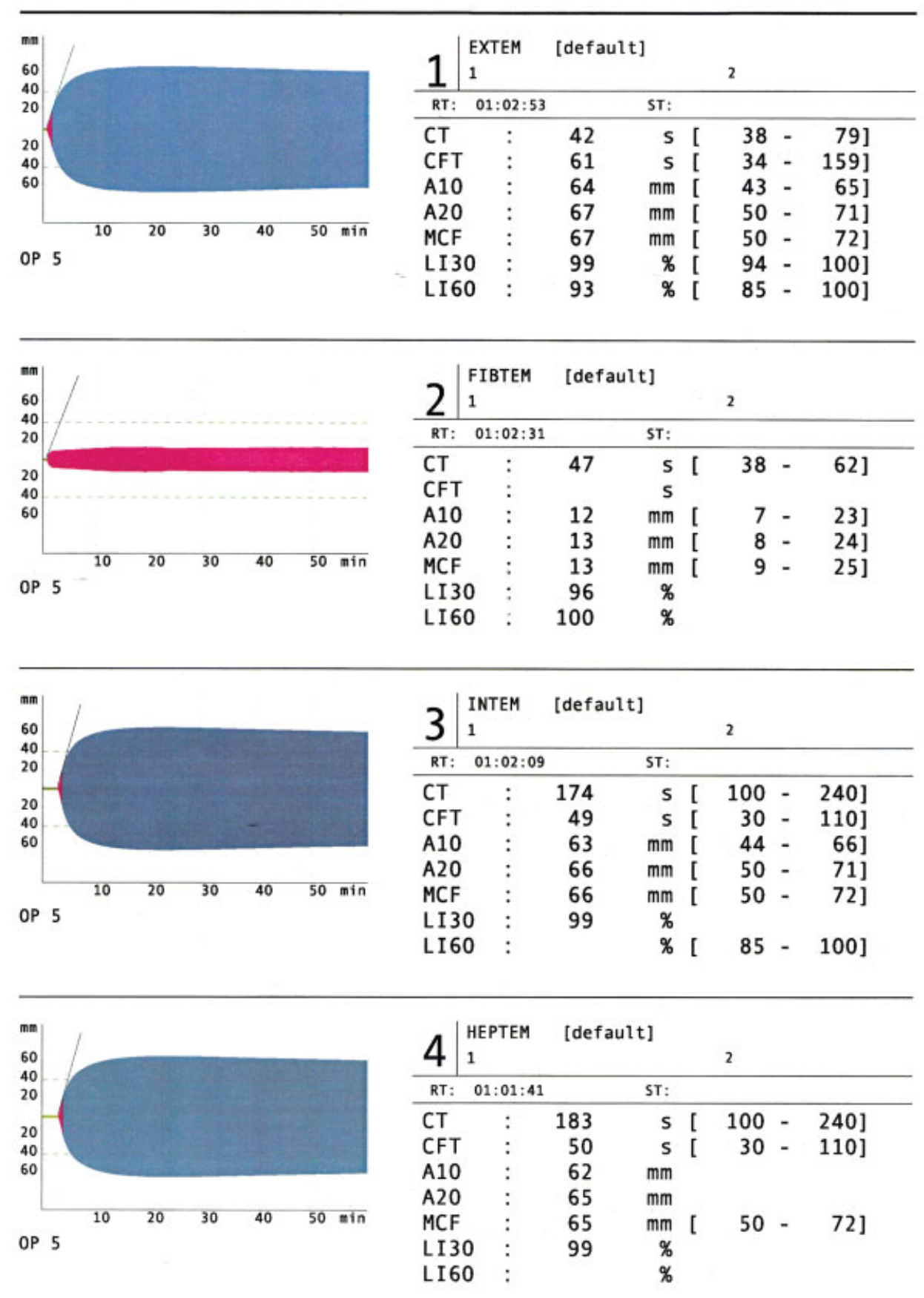

1:PatID/QC-lot 2:SampID/QC-exp

Measurement module $1 / 1$

Fig. 8 Rotational thromboelastometry analysis before starting cardiopulmonary bypass (CPB; correction of aortopulmonary window, 30 days old, $2.4 \mathrm{~kg}$ of body weight, $\mathrm{Hb}$ of $11.7 \mathrm{~g} / \mathrm{dL}$ before $\mathrm{CPB}, \mathrm{Hb}$ of $7.9 \mathrm{~g} / \mathrm{dL}$ on bypass).

storage time should be used, thus limiting the hemolysis induced by mechanical stress, especially when irradiated PRBCs are necessary.

Homologous blood is now added routinely by the great majority of perfusionists in the priming solution to run $\mathrm{CPB}$ in pediatric patients. ${ }^{72}$ Our message is that its use can safely be waived, even in low-weight neonates ( $<2.5 \mathrm{~kg}$ ), by adopting the described multidisciplinary blood sparing strategy.
The amount of homologous blood used during cardiac surgery can be significantly reduced. This approach has been reported to be associated with lower postoperative morbidity and mortality.

We conclude that with the modifications described in this study, bloodless CPB circuit priming should become a widespread reality, even in neonates and young infants, in any open-heart procedure. 


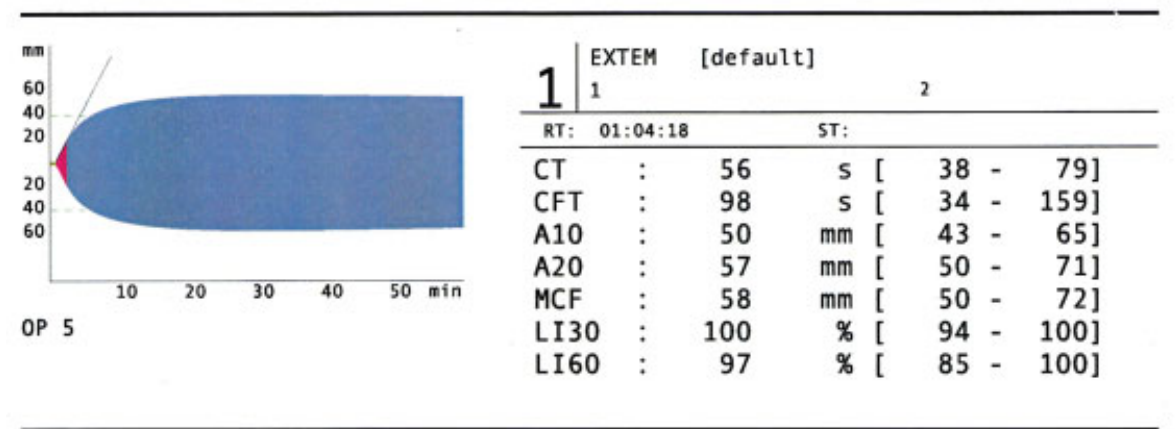

\begin{tabular}{|c|c|c|c|c|c|c|c|c|c|c|c|}
\hline \multirow{2}{*}{\begin{tabular}{l|}
$\mathrm{ma}$ \\
60 \\
40 \\
20
\end{tabular}} & & & & & \multicolumn{2}{|c|}{$\begin{array}{l}\text { FIBTEM } \\
1\end{array}$} & \multicolumn{2}{|c|}{ [default] } & \multicolumn{3}{|c|}{2} \\
\hline & & & & & RT: & $01: 03: 56$ & & ST: & & & \\
\hline $\begin{array}{l}20 \\
40\end{array}$ & & & & & $\begin{array}{l}\mathrm{CT} \\
\mathrm{CFT}\end{array}$ & : & 62 & $\begin{array}{ll}s & {[} \\
s & \end{array}$ & 38 & - & 62] \\
\hline 60 & & & & & $\begin{array}{l}\text { A10 } \\
\text { A20 }\end{array}$ & : & $\begin{array}{r}9 \\
10\end{array}$ & $\begin{array}{l}\mathrm{mm} \\
\mathrm{mm}\end{array}$ & $\begin{array}{l}7 \\
8\end{array}$ & - & $\begin{array}{l}23] \\
24]\end{array}$ \\
\hline$O P$ & 10 & 20 & 30 & $40 \quad 50 \mathrm{~min}$ & $\begin{array}{l}\text { MCF } \\
\text { LI } 30 \\
\text { LI } 60\end{array}$ & $\begin{array}{l}: \\
: \\
:\end{array}$ & $\begin{array}{r}10 \\
100 \\
100\end{array}$ & $\begin{array}{c}\mathrm{mm} \\
\% \\
\%\end{array}$ & 9 & - & 25] \\
\hline
\end{tabular}

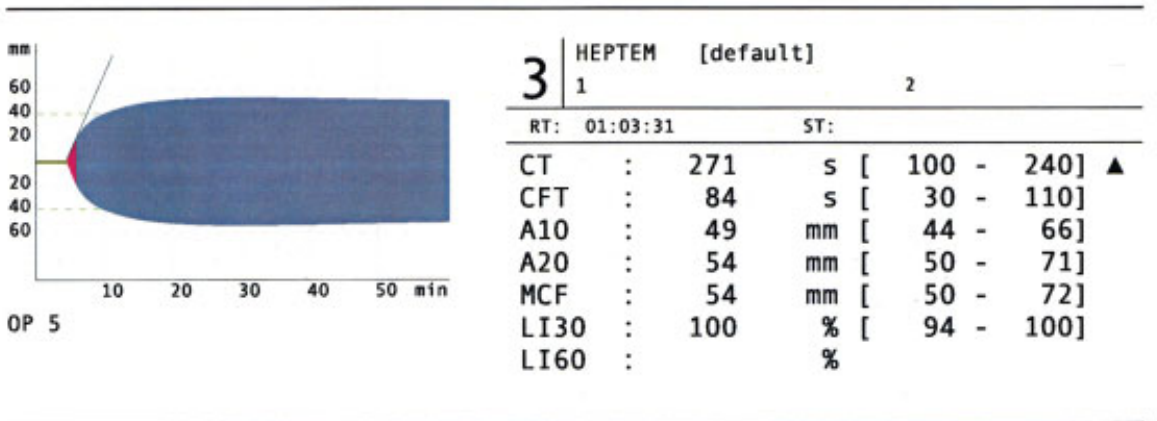

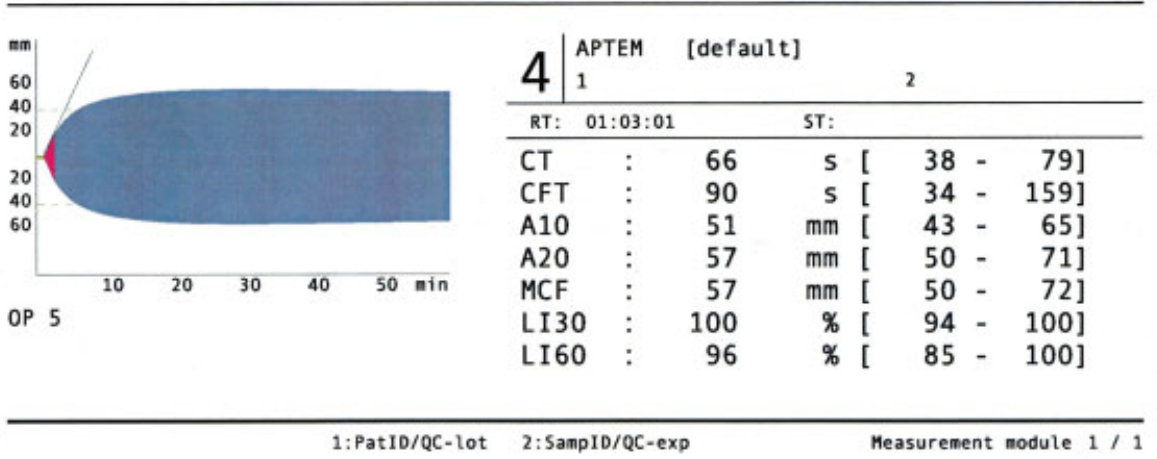

Fig. 9 Rotational thromboelastometry analysis before terminating cardiopulmonary bypass. 


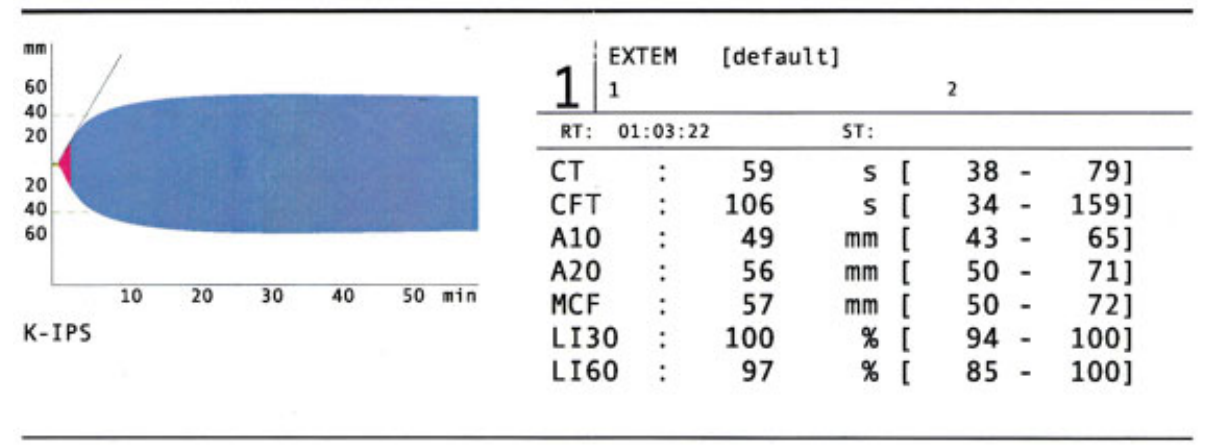

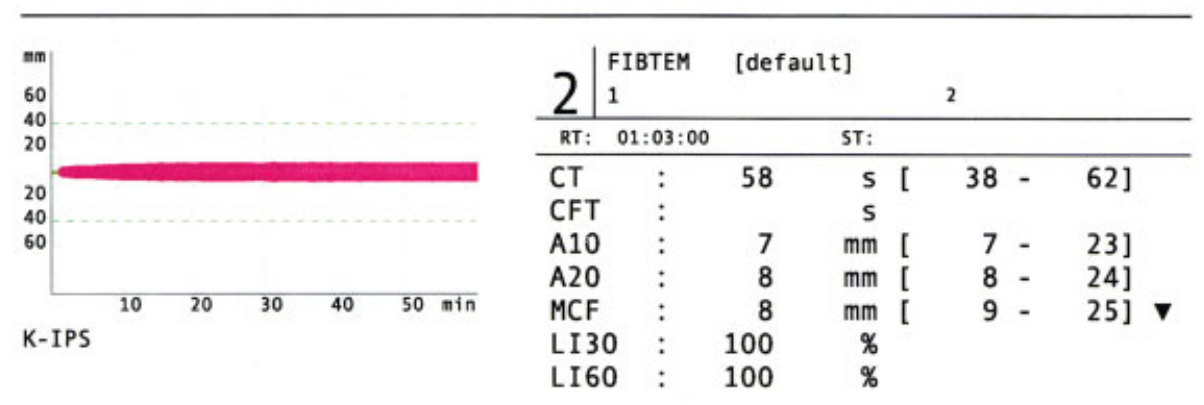

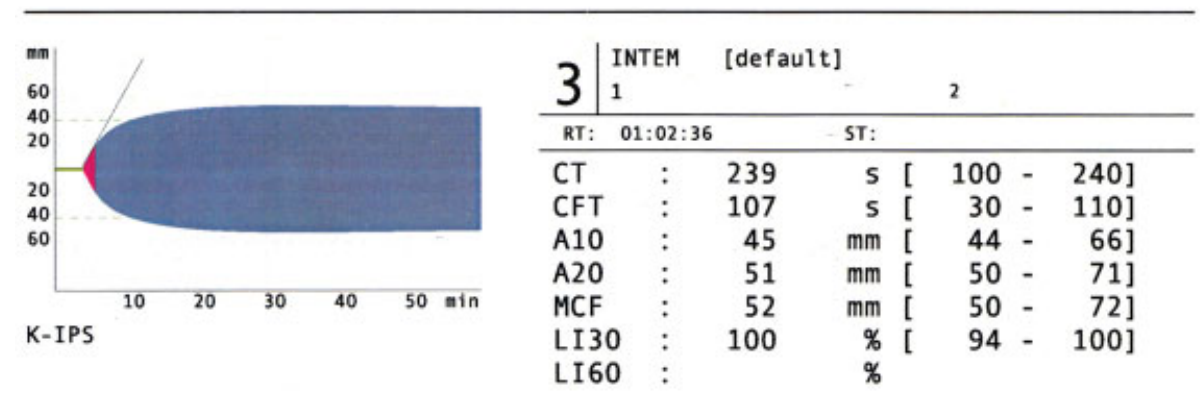

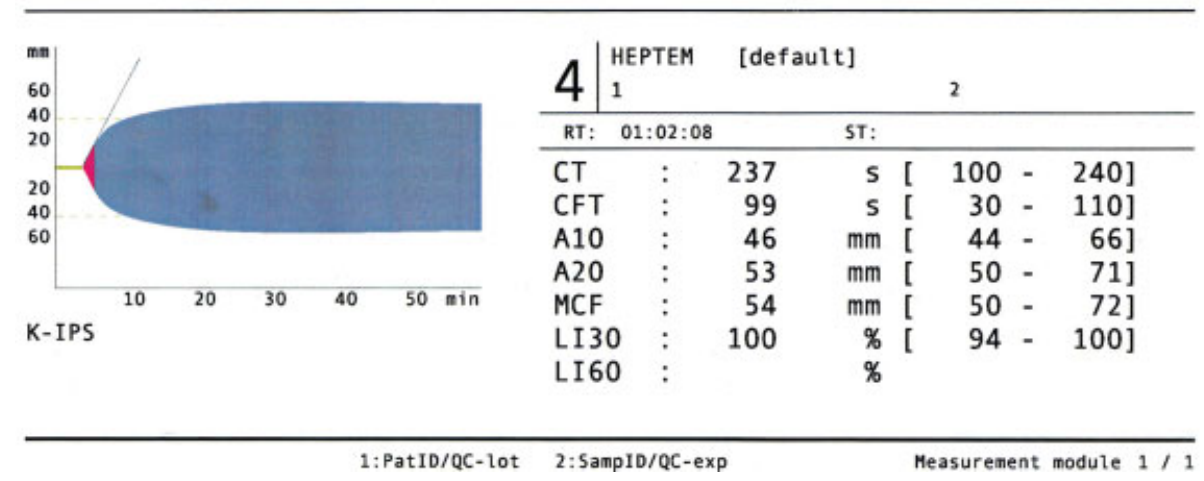

Fig. 10 Postoperative rotational thromboelastometry analysis (intensive care unit) after transfusion of 100-mL packed red blood cells.

Conflict of Interest None.

\section{References}

1 Cooley DA, Frazier $\mathrm{OH}$. The past 50 years of cardiovascular surgery. Circulation 2000;102(20, Suppl 4):IV87-IV93

2 Neptune WB, Panico FG, Bougas JA. Clinical use of pump-oxygenator without donor blood for priming of support during extracorporeal perfusion. Circulation 1959;20:745-746
3 Panico FG, Neptune WB. A mechanism to eliminate the donor blood prime from the pump-oxygenator. Surg Forum 1960;10:605-609

4 Proctor E, De Bono AH. A low priming volume oxygenator for bloodless priming in cardiopulmonary bypass. Thorax 1965;20 (06):540-544

5 Society of Thoracic Surgeons Blood Conservation Guideline Task Force, Ferraris VA, Ferraris SP, et al. Perioperative blood transfusion and blood conservation in cardiac surgery: the Society of Thoracic Surgeons and The Society of Cardiovascular Anesthesiologists clinical practice guideline. Ann Thorac Surg 2007;83(5, Suppl):S27-S86 
6 Kozik DJ, Tweddell JS. Characterizing the inflammatory response to cardiopulmonary bypass in children. Ann Thorac Surg 2006;81 (06):S2347-S2354

7 Richmond ME, Charette K, Chen JM, Quaegebeur JM, Bacha E. The effect of cardiopulmonary bypass prime volume on the need for blood transfusion after pediatric cardiac surgery. JThorac Cardiovasc Surg 2013;145(04):1058-1064

8 Sturmer D, Beaty C, Clingan S, Jenkins E, Peters W, Si MS. Recent innovations in perfusion and cardiopulmonary bypass for neonatal and infant cardiac surgery. Transl Pediatr 2018;7(02):139-150

9 Baffes TG, Riker WL, Deboer A. Open-heart surgery for infants and small children. Mortality and morbidity. Arch Surg 1964; 88:675-680

10 Barratt-Boyes BG, Neutze JM, Seelye ER, Simpson M. Complete correction of cardiovascular malformations in the first year of life. Prog Cardiovasc Dis 1972;15(03):229-253

11 Subramanian S, Wagner H, Vlad P, Lambert E. Surface-induced deep hypothermia in cardiac surgery. J Pediatr Surg 1971;6(05): 612-617

12 Buckley MJ, Austen WG, Goldblatt A, Laver MB. Severe hemodilution and autotransfusion for surgery of congenital heart disease. Surg Forum 1971;22:160-162

13 Turina M, Housman LB, Intaglietta M, Schauble J, Braunwald NS. An automatic cardiopulmonary bypass unit for use in infants. Trans Am Soc Artif Intern Organs 1971;17:376-380

14 Housman LB, Turina M, Braunwald NS. Use of hemodilution during total cardiopulmonary bypass in neonates: experimental evaluation employing a miniaturized heart-lung machine. Surgery 1972;72(03):460-465

15 Turina M, Housman LB, Intaglietta M, Schauble J, Braunwald NS. An automated cardiopulmonary bypass unit for use in infants. J Thorac Cardiovasc Surg 1972;63(02):263-268

16 Levinsky L, Srinivasan V, Choh JH, et al. Intracardiac surgery in children of Jehovah's Witnesses. Johns Hopkins Med J 1981;148 (05):196-198

17 Kawaguchi A, Bergsland J, Subramanian S. Total bloodless open heart surgery in the pediatric age group. Circulation 1984;70(3 Pt 2):I30-I37

18 Henling CE, Carmichael MJ, Keats AS, Cooley DA. Cardiac operation for congenital heart disease in children of Jehovah's Witnesses. J Thorac Cardiovasc Surg 1985;89(06):914-920

19 Stein JI, Gombotz H, Rigler B, Metzler H, Suppan C, Beitzke A. Open heart surgery in children of Jehovah's Witnesses: extreme hemodilution on cardiopulmonary bypass. Pediatr Cardiol 1991;12 (03):170-174

20 Wabeke E, Elstrodt JM, Mook PH, Gathier S, Wildevuur CR. Clear prime for infant cardiopulmonary bypass: a miniaturized circuit. J Cardiovasc Surg (Torino) 1988;29(02):117-122

21 Taketani S, Sawa Y, Masai T, et al. A novel technique for cardiopulmonary bypass using vacuum system for venous drainage with pressure relief valve: an experimental study. Artif Organs 1998;22(04):337-341

22 Darling E, Kaemmer D, Lawson S, et al. Experimental use of an ultra-low prime neonatal cardiopulmonary bypass circuit utilizing vacuum-assisted venous drainage. JExtra Corpor Technol 1998;30(04):184-189

23 Wabeke E, Mook PH, Elstrodt JM, et al. An automatically regulated low prime heart-lung machine for infants: a rabbit model. Perfusion 1987;2:109-113

24 von Segesser L, Leskosek B, Redha F, Garcia E, Turina M. Experimental evaluation of the Dideco Masterflo paediatric hollowfibre membrane oxygenator. Perfusion 1989;4:223-234

25 Dubois J, Jamaer L, Mees U, et al. Ex vivo evaluation of a new neonatal/infant oxygenator: comparison of the Terumo CAPIOX Baby RX with Dideco Lilliput 1 and Polystan Safe Micro in the piglet model. Perfusion 2004;19(05):315-321

26 Conley JC, Zografos CA. Bloodless prime in pediatric cardiopulmonary bypass circuits. J Extra Corpor Technol 1991;23:80-82
27 Boettcher W, Merkle F, Koster A, et al. Safe minimization of cardiopulmonary bypass circuit volume for complex cardiac surgery in a $3.7 \mathrm{~kg}$ neonate. Perfusion 2003;18(06):377-379

28 Wloch A, Boettcher W, Sinzobahamvya N, et al. Bloodless priming of the cardiopulmonary bypass circuit: determinants of successful transfusion-free operation in neonates and infants with a maximum body weight of $7 \mathrm{~kg}$. Cardiol Young 2018;28(10):1141-1147

29 Boettcher W, Redlin M, Dehmel F, et al. Asanguineous priming of miniaturized paediatric cardiopulmonary bypass circuits for congenital heart surgery: independent predictors associated with transfusion requirements and effects on postoperative morbidity. Eur J Cardiothorac Surg 2018;53(05):1075-1081

30 Huebler M, Redlin M, Boettcher W, et al. Transfusion-free arterial switch operation in a 1.7-kg premature neonate using a new miniature cardiopulmonary bypass system. JCard Surg 2008;23 (04):358-360

31 Koster A, Huebler M, Boettcher W, Redlin M, Berger F, Hetzer R. A new miniaturized cardiopulmonary bypass system reduces transfusion requirements during neonatal cardiac surgery: initial experience in 13 consecutive patients. JThorac Cardiovasc Surg 2009;137(06):1565-1568

32 Redlin M, Koster A, Huebler M, et al. Regional differences in tissue oxygenation during cardiopulmonary bypass for correction of congenital heart disease in neonates and small infants: relevance of near-infrared spectroscopy. J Thorac Cardiovasc Surg 2008;136 (04):962-967

33 Boettcher W, Sinzobahamvya N, Miera O, et al. Routine application of bloodless priming in neonatal cardiopulmonary bypass: a 3-year experience. Pediatr Cardiol 2017;38(04):807-812

34 Ando M, Takahashi Y, Suzuki N. Open heart surgery for small children without homologous blood transfusion by using remote pump head system. Ann Thorac Surg 2004;78(05):1717-1722

35 Horisberger J, Jegger D, Boone Y, et al. Impact of a remote pump head on neonatal priming volumes. Perfusion 1999;14(05):351-356

36 Merkle F, Boettcher W, Schulz F, Koster A, Huebler M, Hetzer R. Perfusion technique for nonhaemic cardiopulmonary bypass prime in neonates and infants under $6 \mathrm{~kg}$ body weight. Perfusion 2004;19(04):229-237

37 Datt B, Nguyen MB, Plancher G, et al. The impact of roller pump vs. centrifugal pump on homologous blood transfusion in pediatric cardiac surgery. J Extra Corpor Technol 2017;49(01):36-43

38 Bonchek LI, Starr A. Intracardiac surgery in infants with conventional cardiopulmonary bypass. In: Ionescu MI, Wooler GH, eds. Techniques in Extracorporeal Circulation. London: Butterworths; 1976:229-244

39 Morgan IS, Codispoti M, Sanger K, Mankad PS. Superiority of centrifugal pump over roller pump in paediatric cardiac surgery: prospective randomised trial. Eur J Cardiothorac Surg 1998;13 (05):526-532

40 Durandy Y. Vacuum-assisted venous drainage, angel or demon: PRO? J Extra Corpor Technol 2013;45(02):122-127

41 Durandy Y. The impact of vacuum-assisted venous drainage and miniaturized bypass circuits on blood transfusion in pediatric cardiac surgery. ASAIO J 2009;55(01):117-120

42 Chambers SD, Ceccio SL, Annich GA, Bartlett RH. Extreme negative pressure does not cause erythrocyte damage in flowing blood. ASAIO J 1999;45(05):431-435

43 El-Sabbagh AM, Toomasian CJ, Toomasian JM, Ulysse G, Major T, Bartlett RH. Effect of air exposure and suction on blood cell activation and hemolysis in an in vitro cardiotomy suction model. ASAIO J 2013;59(05):474-479

44 Machin DA, Allsager C. Principles of cardiopulmonary bypass. Contin Educ Anaesth Crit Care Pain 2006;6:176-181

45 Redlin M, Boettcher W, Dehmel F, Cho MY, Kukucka M, Habazettl H. Accuracy of predicted haemoglobin concentration on cardiopulmonary bypass in paediatric cardiac surgery: effect of different formulae for estimating patient blood volume. Perfusion 2017;32(08):639-644 
46 McRobb CM, Ing RJ, Lawson DS, Jaggers J, Twite M. Retrospective analysis of eliminating modified ultrafiltration after pediatric cardiopulmonary bypass. Perfusion 2017;32(02):97-109

47 Koster A, Fischer T, Praus M, et al. Hemostatic activation and inflammatory response during cardiopulmonary bypass: impact of heparin management. Anesthesiology 2002;97(04):837-841

48 Culliford AT, Gitel SN, Starr N, et al. Lack of correlation between activated clotting time and plasma heparin during cardiopulmonary bypass. Ann Surg 1981;193(01):105-111

49 Despotis GJ, Summerfield AL, Joist JH, et al. Comparison of activated coagulation time and whole blood heparin measurements with laboratory plasma anti-Xa heparin concentration in patients having cardiac operations. JThorac Cardiovasc Surg 1994;108(06):1076-1082

50 Ammar T, Fisher CF, Sarier K, Coller BS. The effects of thrombocytopenia on the activated coagulation time. Anesth Analg 1996;83 (06):1185-1188

51 Gruenwald CE, Manlhiot C, Chan AK, et al. Randomized, controlled trial of individualized heparin and protamine management in infants undergoing cardiac surgery with cardiopulmonary bypass. JAm Coll Cardiol 2010;56(22):1794-1802

52 Guzzetta NA, Bajaj T, Fazlollah T, et al. A comparison of heparin management strategies in infants undergoing cardiopulmonary bypass. Anesth Analg 2008;106(02):419-425

53 Durandy Y. Warm pediatric cardiac surgery: European experience. Asian Cardiovasc Thorac Ann 2010;18(04):386-395

54 Valeri CR, Collins FB. The physiologic effect of transfusing preserved red cells with low 2,3-diphosphoglycerate and high affinity for oxygen. Vox Sang 1971;20(05):397-403

55 Ho J, Sibbald WJ, Chin-Yee IH. Effects of storage on efficacy of red cell transfusion: when is it not safe? Crit Care Med 2003;31(12, Suppl):S687-S697

56 Berezina TL, Zaets SB, Morgan C, et al. Influence of storage on red blood cell rheological properties. J Surg Res 2002;102(01):6-12

57 Rother RP, Bell L, Hillmen P, Gladwin MT. The clinical sequelae of intravascular hemolysis and extracellular plasma hemoglobin: a novel mechanism of human disease. JAMA 2005;293(13):1653-1662

58 Kanias T, Gladwin MT. Nitric oxide, hemolysis, and the red blood cell storage lesion: interactions between transfusion, donor, and recipient. Transfusion 2012;52(07):1388-1392

59 Matsuki O, Matsuda H, Shimazaki Y, et al. Open heart surgery without homologous blood transfusion in small children of body weight less than $20 \mathrm{~kg}$ [in Japanese]. Nihon Kyobu Geka Gakkai Zasshi 1992;40(02):235-241
60 Tsang VT, Mullaly RJ, Ragg PG, Karl TR, Mee RB. Bloodless open-heart surgery in infants and children. Perfusion 1994;9(04):257-263

61 Miyaji K, Kohira S, Miyamoto T, et al. Pediatric cardiac surgery without homologous blood transfusion, using a miniaturized bypass system in infants with lower body weight. JThorac Cardiovasc Surg 2007;134(02):284-289

62 Kotani Y, Honjo O, Nakakura M, et al. Single center experience with a low volume priming cardiopulmonary bypass circuit for preventing blood transfusion in infants and small children. ASAIO J 2009;55(03):296-299

63 De Rita F, Marchi D, Lucchese G, et al. Comparison between D901 Lilliput 1 and Kids D100 neonatal oxygenators: toward bypass circuit miniaturization. Artif Organs 2013;37(01):E24-E28

64 Chang HW, Nam J, Cho JH, Lee JR, Kim YJ, Kim WH. Five-year experience with mini-volume priming in infants $\leq 5 \mathrm{~kg}$ : safety of significantly smaller transfusion volumes. Artif Organs 2014;38 (01):78-87

65 Kwak JG, Park M, Lee J, Lee CH. Multiple approaches to minimize transfusions for pediatric patients in open-heart surgery. Pediatr Cardiol 2016;37(01):44-49

66 Cho MY, Boettcher W, Redlin M, et al. Open-heart surgery in neonates: current practice. JCardiovasc Surg (Torino) 2018;59 (02):299-301

67 Murin P, Boettcher W, Ozaki S, et al. Asanguineous cardiopulmonary bypass in infants: impact on postoperative mortality and morbidity. Thorac Cardiovasc Surg 2019 (e-pub ahead of print) Doi: $10.1055 / \mathrm{s}-0038-1676789$

68 O'Brien SM, Clarke DR, Jacobs JP, et al. An empirically based tool for analyzing mortality associated with congenital heart surgery. J Thorac Cardiovasc Surg 2009;138(05):1139-1153

69 Redlin M, Boettcher W, Kukucka M, Kuppe H, Habazettl H. Blood transfusion during versus after cardiopulmonary bypass is associated with postoperative morbidity in neonates undergoing cardiac surgery. Perfusion 2014;29(04):327-332

70 de Gast-Bakker DH, de Wilde RB, Hazekamp MG, et al. Safety and effects of two red blood cell transfusion strategies in pediatric cardiac surgery patients: a randomized controlled trial. Intensive Care Med 2013;39(11):2011-2019

71 Mahan LV. Recent advances in neonatal cardiac surgery - Hematocrit. In Advances in Cardiothoracic Surgery; Avid Science eBook 2016, www.avidscience.com: 16-17

72 Kartha VM, Jacobs JP, Vener D, et al. National benchmarks of proportions of patients receiving transfusions during pediatric heart surgery. Ann Thorac Surg 2018;106:1197-1203 